\title{
Indicadores de especialização das exportações brasileiras de petróleo: evidências para o período de 2000 a 2018
}

\author{
Specialization indicators of brazilian oil exports: evidence for the period \\ from 2000 to 2018
}

Rafael Moraes de SousaI, Michele Polline Veríssimo ${ }^{I I}$

\begin{abstract}
RESUMO
As exportações brasileiras de petróleo bruto apresentaram ótimo desempenho a partir dos anos 2000, sendo que o produto se tornou o segundo mais exportado pelo país em 2018. Aliado a isso, a descoberta do petróleo nas reservas do Pré-sal e o aumento dos preços internacionais das commodities, ao mesmo tempo em que proporcionam vantagens comparativas para o Brasil no comércio internacional deste produto, geram a preocupação sobre o aprofundamento do processo de especialização na exportação de produtos primários (reprimarização). Este trabalho busca verificar se o petróleo bruto vem adquirindo relevância no comércio internacional brasileiro por meio da elaboração de alguns indicadores de especialização das exportações no período 2000-2018. Os resultados obtidos indicam um processo de especialização em curso nas exportações de petróleo bruto para o Brasil nos últimos anos.
\end{abstract}

Palavras-chave: Exportações; petróleo; especialização; indicadores; Brasil.

\section{ABSTRACT}

Brazilian crude oil exports have performed very well since the 2000s, with the product becoming the second most exported by the country in 2018. Added to this, the discovery of oil in the Pre-salt reserves and high international commodities prices, while providing comparative advantages for Brazil in the international trade of this product, raises concern about the deepening of the specialization process in the primary products exports (reprimarization). This paper aims to investigate whether crude oil has been gaining relevance in Brazilian international trade through the development of some indicators of export specialization in the period 2000-2018. The results obtained indicate a specialization process underway in crude oil exports to Brazil in recent years.

Keywords: Exports; Oil; Specialization; Indicators; Brazil.

\section{INTRODUÇÃO}

A economia brasileira é caracterizada pela expressiva participação dos produtos primários na pauta exportadora, os quais, segundo dados do MDIC (2020) somaram $52,8 \%$ do total das exportações em 2018. Dentre os principais produtos da pauta, 0 petróleo ganha destaque ao longo do tempo, se tornando o terceiro principal produto exportado pelo Brasil em 2018, e atingindo o segundo lugar em 2019, com participação de $10,7 \%$, ao lado de soja $(11,6 \%)$ e minério de ferro $(10 \%)$. Soma-se a isso a descoberta de grandes reservas de petróleo nas camadas do Pré-sal em 2006, o que,

II Professora do Instituto de Economia da Universidade Federal de Uberlândia (IEUFU) - micheleverissimo@ufu.br 
mediante a exploração da nova fonte do recurso, implica a possibilidade de o país se tornar um grande produtor desse bem e menos dependente das importações do produto. Deste modo, a expressividade obtida pelo petróleo no conjunto das exportações brasileiras nos últimos anos enseja uma discussão sobre um possível processo de especialização do país em commodities energéticas, para além das commodities agrícolas e minerais.

Sobre a perspectiva do petróleo no comércio mundial, ainda que exista uma tendência em desenvolver novas matrizes energéticas, sobretudo, diante de um maior engajamento no cenário internacional em debater vias de desenvolvimento mais inclinadas com a sustentabilidade ambiental e a propagação de matrizes baseadas em energia renovável, o petróleo ainda figura como principal recurso energético, representando, em 2018, cerca de $31,5 \%$ da fonte energética mundial. Ainda nesse ano, a produção mundial correspondeu a 94,7 milhões de barris/dia, enquanto o consumo mundial foi cerca de 99,8 milhões de barris/dia, algo em torno de 1,43 milhão de barris/dia consumidos a mais se comparado ao ano de 2017 (ANP, 2018). Para efeito comparativo, as demais fontes energéticas representaram a seguinte distribuição: Carvão Mineral (26,9 \%); Gás Natural (22,8 \%); Nuclear (4,9 \%); Outrosincluindo renováveis (Biomassa, hidráulica, etc..)- (13,5\%); e Não identificadas $(0,4$ \%) (EPE, 2019).

Diante desse panorama, é razoável presumir que o petróleo seja um produto estratégico. Contudo, a literatura econômica aponta divergências em relação às vantagens decorrentes de um processo de especialização baseado em bens primários. Nestes termos, a teoria sobre a Maldição dos Recursos Naturais, por exemplo, pressupõe que economias abundantes em recursos naturais tendem a apresentar menores taxas de crescimento econômico no longo prazo (SACHS; WARNER, 1995). Tal efeito deriva de um contexto de alta dos preços das commodities e de apreciação cambial que podem resultar em um cenário prejudicial à competitividade do setor industrial. Além disso, toma-se que a dependência das receitas provenientes da exploração de bens primários dificulta a condução de investimentos, dada a alta volatilidade dos preços desses bens, que também tendem a ser menos sensíveis aos aumentos de renda ao longo do tempo. Por fim, ressalta-se que, em um cenário de fragilidade institucional, a abundância de recursos naturais facilita a utilização das receitas obtidas em atividades rent-seeking, favorecendo a corrupção e a burocracia na gestão dos contratos, além de práticas protecionistas aos setores primários dominantes (FRANKEL, 2010; VAN DER PLOEG, 2011).

Neste sentido, a partir da análise de dados sobre o desempenho exportador do setor petrolífero no período de 2000 a 2018, este artigo pretende avaliar a ocorrência de um processo de especialização das exportações em petróleo no Brasil. Para tanto, pressupõe-se que o aumento das exportações do petróleo no período, sobretudo, com o avanço da exploração das reservas do Pré-sal, poderá acentuar o predomínio dos produtos primários na composição da pauta comercial. 
A metodologia utilizada se baseia no cálculo de alguns indicadores tradicionais de especialização comercial, que visam determinar a existência (ou não) de vantagem comparativa e melhor posicionamento do setor no mercado externo, sendo eles o Índice de Vantagem Comparativa Revelada (VCR) proposto por Balassa (1989), e o Índice de Vantagem Competitiva Revelada (VCR) e o Índice de Posição Relativa no Mercado (POS) sugeridos por Lafay et al. (1999).

O artigo está estruturado em seis seções, além desta introdução. A segunda seção apresenta os argumentos teóricos sobre a relação entre padrão de especialização das exportações e desempenho econômico. A terceira seção descreve o comportamento comercial e produtivo do setor de petróleo ao longo dos anos 2000. A quarta seção discorre sobre a metodologia utilizada na elaboração dos indicadores de especialização comercial. A quinta seção expõe os resultados obtidos para os indicadores. A última seção apresenta as considerações finais

\section{PADRÃO DE ESPECIALIZAÇÃO DAS EXPORTAÇÕES E CRESCIMENTO ECONÔMICO}

Dentre as diversas abordagens que focam na explicação do crescimento econômico, verifica-se uma discussão direcionada para a relevância do desempenho do setor exportador, sobretudo, no que tange ao impacto direto sobre a estrutura produtiva de um país, na medida em que determina os setores mais competitivos e, portanto, com maiores potenciais de crescimento (NAKABASHI ET AL., 2008).

Autores como Kaldor e Thirlwall, dentre outros, argumentam que as exportações, sobretudo as de origem industrial, por suas maiores elasticidades-renda, são relevantes para explicar o desempenho de um país no longo prazo. O desempenho exportador é reflexo das decisões e impactos macroeconômicos (tais como câmbio, juros, tarifas etc...) internos e externos, de modo que também é um fiel retrato de quais setores da economia são mais competitivos internacionalmente. Desse modo, mudanças em sua composição causam alterações na posição dos setores mais competitivos da economia, o que altera a dinâmica econômica, dependendo do grau de dinamismo e encadeamento dos segmentos que estão perdendo e dos que estão ganhando participação (CRUZ ET AL, 2007).

A partir da perspectiva de um papel relevante da composição da pauta exportadora para o crescimento econômico, abre-se espaço para dialogar com outras teorias, sobretudo, as relacionadas com o comércio internacional e o padrão de especialização de uma nação. Resgatando conceitos clássicos, Smith e Ricardo, por exemplo, já recomendavam a especialização produtiva mediante as análises das vantagens de custos absolutas e comparativas, reportando os benefícios que tal especialização poderia difundir, respectivamente, sobre a riqueza e o crescimento.

O argumento predominante enfatiza que uma nação deve se especializar naqueles produtos em que assumam maiores vantagens comparativas. Tais vantagens podem se apresentar em diversos fatores, como mão de obra, capital, tecnologia e 
recursos naturais. O principal expoente desse argumento é o modelo de tradição neoclássica Heckscher-Ohlin (1970), partindo do princípio que a dotação de fatores é capaz de explicar as distintas especializações no comércio internacional. Não obstante, diverge quanto à visão ricardiana, que atribui como ponto central a especialização as diferenças de produtividade ou de tecnologias. $O$ argumento central versa que os países tendem a se especializar em bens cuja produção seja intensiva em fatores relativamente abundantes (NASSIF; CASTILHO, 2017).

Contudo, há uma vertente na literatura que aborda as consequências de se migrar para uma especialização baseada em recursos naturais. Neste sentido, a grande questão derivada de um processo de especialização (baseado em recursos naturais) é se há ou não vantagem para a nação. A literatura sobre a Maldição dos Recursos Naturais, por exemplo, pressupõe que economias abundantes em recursos naturais tendem a apresentar menores taxas de crescimento econômico. Nestes termos, o contexto de alta dos preços das commodities e de apreciação cambial que resulta da entrada de divisas relacionadas às vendas daqueles produtos (Doença Holandesa) pode resultar na especialização das exportações em produtos intensivos em recursos naturais, prejudicando os setores industriais, com impactos perversos sobre 0 crescimento econômico (SACHS; WARNER, 1995).

Cabe destacar que a abundância em recursos naturais, per se, não é fator suficiente para apontar uma relação negativa com o crescimento econômico, porquanto o resultado indesejado depende de alguns canais pelos quais a "maldição" pode ser repassada para o desempenho econômico. Conforme Frankel (2010) e Van der Ploeg (2011) resumem, a Maldição dos Recursos Naturais pode ocorrer devido à tendência de longo prazo desfavorável aos preços das commodities, à dificuldade de desenvolvimento do setor manufatureiro; aos efeitos da Doença Holandesa; e à fragilidade das instituições.

Destarte, a Maldição dos Recursos Naturais assinala que um boom de recursos mediante a melhora dos termos de comércio ou descoberta de novas fontes comprime o desenvolvimento do setor industrial ao deslocar os meios de produção (capital e trabalho) para os setores primários ou de bens não comercializáveis (SACHS; WARNER, 1997). Em vista disso, as exportações de bens industriais se tornam menos competitivas, e, por consequência, as economias perdem o crescimento pautado pelas exportações de bens manufaturados. Alguns desdobramentos prejudiciais às economias decorrentes da especialização em recursos naturais são a Doença Holandesa e a desindustrialização.

Corden e Neary (1982) trataram do problema denominado "Doença Holandesa", em que a descoberta de uma nova fonte de recursos naturais, com potencial exportável, ou que apresente elevação significativa e contínua das cotações internacionais, estimula o aumento das exportações desses recursos. Não obstante, há grande entrada de divisas por meio das exportações de modo a induzir uma apreciação da taxa de câmbio real que prejudica a produção de bens comercializáveis. 
Bresser-Pereira (2009) ressalta que a especialização em commodities, oriunda de vantagens comparativas em relação aos concorrentes internacionais, gera um fluxo de divisas obtidas pelo maior volume de exportações desses produtos, apreciando a taxa de câmbio real em patamares inadequados para tornar rentáveis as exportações de bens manufaturados. Oreiro e Feijó (2010) complementam que o direcionamento da pauta de exportações para commodities, produtos primários ou manufaturas com baixo valor adicionado, é tido como um processo negativo, que pode estar associado com os efeitos da Doença Holandesa, causando, em última instância, a desindustrialização da economia, ou seja, a redução da participação industrial tanto no emprego quanto no produto nacional e também nas exportações.

Os efeitos perversos da especialização baseada em recursos naturais, conforme a teoria da Maldição dos Recursos Naturais, também tem correlação com as instituições. Conforme elucidam Robinson et al. (2006), muitas nações abundantes em recursos naturais possuem uma atuação irregular na apropriação das vantagens potenciais de seus recursos devido à fragilidade institucional que conduz à má gestão de contratos, políticas protecionistas aos setores primários, corrupção, aplicação de recursos com direcionamento para atividades não produtivas, dentre outros fatores.

Tais fundamentações teóricas se tornam pertinentes quando associadas ao caso brasileiro. Isto, pois, em 2006, com a descoberta de jazidas que se estendem do estado do Espírito Santo até Santa Catarina, o Pré-sal surgiu como um potencial impulsionador da produção nacional de petróleo, alavancando a posição do Brasil no circuito mundial. Esse fato acendeu a discussão sobre os possíveis efeitos negativos da exploração das novas reservas, tendo em vista a possibilidade de o país caminhar para a Doença Holandesa e a desindustrialização.

A descoberta do petróleo nas reservas do Pré-sal proporciona a possibilidade de alavancar as exportações desta commodity ao longo do tempo, de forma que, para além das commodities agrícolas e minerais, o país pudesse também apresentar especialização em commodities energéticas. Em um cenário positivo, a exploração do Pré-sal é vista como uma oportunidade de obtenção de autossuficiência em petróleo e de melhores saldos comerciais, com geração de emprego e ganhos de receita a serem disseminados para outros setores da economia. Ainda, se prediz a alavancagem da cadeia produtiva petrolífera, que é intensiva em conhecimento e tecnologia, estimulando gastos com Pesquisa e Desenvolvimento (P\&D) e a inovação no país.

Por outro lado, a descoberta do petróleo no Pré-sal pode aprofundar a especialização do país em commodities, com os efeitos negativos apontados anteriormente, como o deslocamento de recursos produtivos para os setores primários, a apreciação cambial pela entrada de divisas pelas exportações do produto e a redução da competitividade dos setores industriais ocasionando um processo de desindustrialização ligado ao problema da Doença Holandesa. Ainda, há o receio de que as receitas obtidas sejam utilizadas em atividades de cunho rentista e promovam a corrupção e a burocracia. 
Portanto, o presente trabalho pretende identificar o avanço da contribuição do petróleo para o padrão de especialização da pauta exportadora brasileira em recursos naturais. Tal perspectiva apreensiva é justificada na hipótese de que o aumento das exportações do petróleo no período de 2000 a 2018, especialmente com o avanço da exploração das reservas do Pré-Sal, poderá agravar a situação do país em termos do predomínio dos produtos primários na composição da pauta comercial.

\section{DESEMPENHO COMERCIAL DO SETOR DE PETRÓLEO NOS ANOS 2000}

Mesmo diante de uma maior pressão no cenário mundial em desenvolver novas matrizes energéticas, o petróleo permanece como o principal recurso energético, representando, em 2018, cerca de $31 \%$ da fonte energética mundial (EPE, 2019). Ainda nesse ano, a produção mundial correspondeu a 94,7 milhões de barris/dia, enquanto o consumo mundial foi cerca de 99,8 milhões de barris/dia, algo em torno de 1,43 milhão de barris/dia consumidos a mais se comparado ao ano de 2017 (ANP, 2018).

Diante da perspectiva internacional e de uma demanda global ainda crescente por petróleo, a descoberta de novas fontes do produto nas reservas do Pré-sal impulsiona o Brasil a um novo potencial produtivo, o que também o credencia a tornarse um importante ator da geopolítica mundial. Estima-se que a quantidade de petróleo das jazidas do Pré-sal ${ }^{11}$ seja de aproximadamente 100 bilhões de barris, e o crescimento previsto na produção petrolífera do país é de $2,9 \%$ até 2030 , sendo que, ao final desse período, o Brasil possuirá capacidade de produzir 3,4 milhões de barris diários (IEA, 2009).

Em 2018, de acordo com dados do MDIC (2020), as exportações de óleo bruto de petróleo representaram $10,7 \%$ das exportações totais e $47,8 \%$ dentre os produtos básicos, alcançando o patamar de segundo produto no ranking da pauta comercial brasileira. Em ambos os casos, o petróleo bruto só fica atrás de outra commodity, a soja triturada, sendo que ultrapassou as vendas de minério de ferro.

Em 18 anos, a produção brasileira de petróleo mais que dobrou, com notáveis $110 \%$ de ampliação, o que representa uma diferença produtiva de 1,4 milhão de barris/dia. Também obteve expansão de participação na produção mundial, passando de $1,7 \%$ para $2,83 \%$ no período de análise. Vale ressaltar que, a partir de 2014 , o principal playernacional, a Petrobras, tornou-se alvo de uma investigação de combate à corrupção em seu quadro institucional - a Operação Lava Jato, o que trouxe impactos negativos repercutindo em desinvestimentos na atividade. No entanto, a estratégia de

\footnotetext{
${ }^{1}$ Segundo a Petrobras (2019), o Pré-sal é uma sequência de rochas sedimentares formadas há mais de 100 milhões de anos no espaço geográfico criado pela separação dos continentes americano e africano, que começou há cerca de 150 milhões de anos. Entre os dois continentes formaram-se, inicialmente, grandes depressões, que deram origem a grandes lagos, onde foram depositadas as rochas geradoras de petróleo do Pré-sal.
} 
exploração do Pré-sal foi mantida, o que garantiu a produção crescente, embora aquém das projeções inicialmente feitas para o período.

$\mathrm{Na}$ comparação internacional, em 2018, os Estados Unidos possuíram a liderança em produção mundial com volume médio de 15,3 milhões de barris/dia, seguidos pela Arábia Saudita, com 12,2 milhões de barris/dia, e pela Rússia, com 11,4 milhões de barris/dia. Essa tríade representa $41,2 \%$ de toda a produção mundial, sendo que o Brasil, segundo dados do BP Group (2019), aparece na décima posição.

O Brasil também avançou em sua autossuficiência, reduzindo a diferença entre consumo e produção em 37,5\% em 18 anos. Tal diferença representa 4,71 milhões de barris/dia. Parte do crescimento da produção é direcionada ao consumo interno, reduzindo, assim, a dependência de importações. Ademais, o consumo nacional se elevou em 48\%, passando de 2,48 milhões de barris/dia em 2000 para 3,01 milhões de barris/dia em 2017, posicionando o país como o sétimo maior consumidor, responsável por 3,1\% da demanda mundial. Cabe destacar que, segundo dados do BP Group (2019), Estados Unidos e China, juntos, respondem por 33,2\% do consumo mundial de petróleo.

O Gráfico 1 apresenta a evolução da produção brasileira de petróleo no período de 2000 a 2018, bem como a sua participação relativa na produção mundial.

Gráfico 1 - Produção, consumo de petróleo no Brasil (milhares de barris/dia) e participação mundial da produção brasileira (\%) (2000-2018)

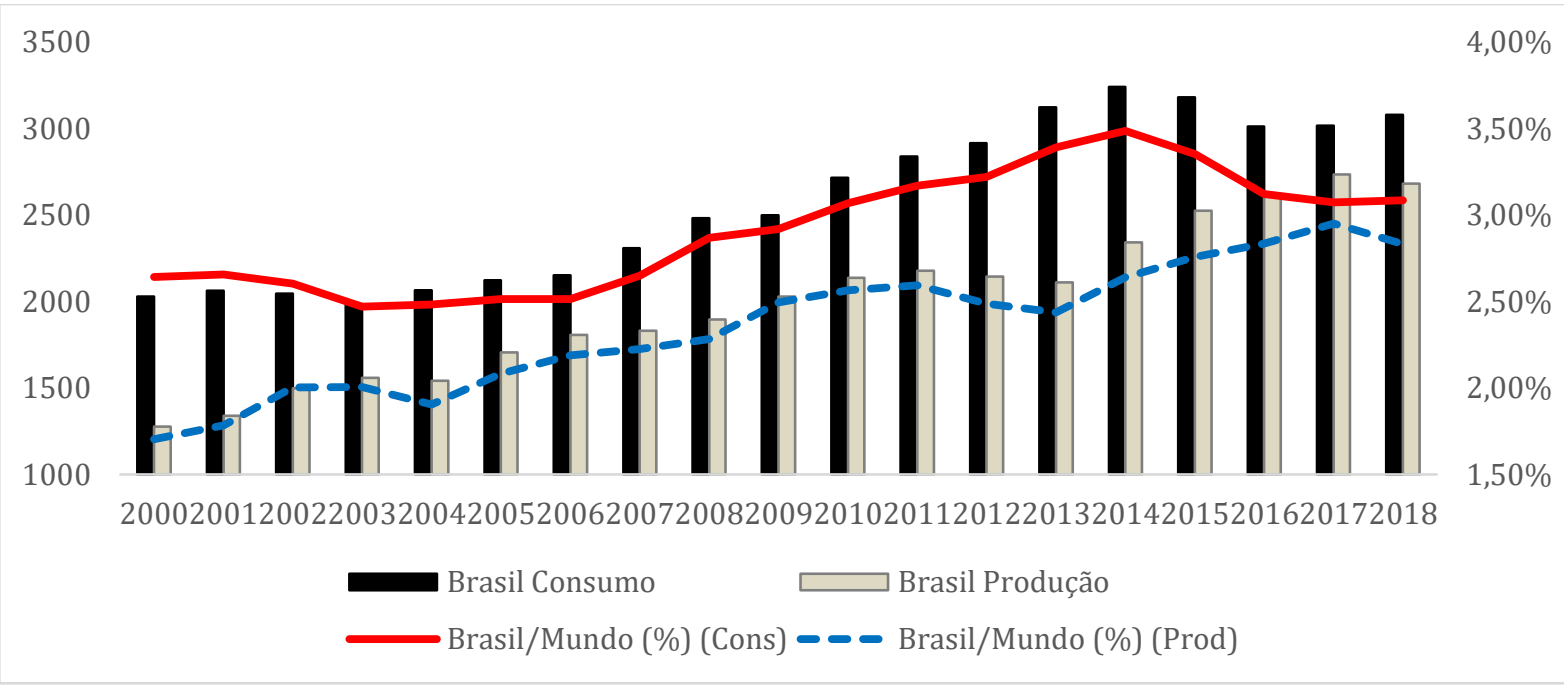

Fonte: Elaboração própria a partir dos dados do BP Group (2019).

É preciso atentar para a contribuição das reservas do Pré-sal nos resultados. De acordo com dados da ANP (2019), o aumento da produção nacional está atrelado à expressiva elevação da produção no Pré-sal, que, em 2008, representava menos de $1 \%$ da produção total, com agregação de 2,558 milhões de barris. A produção de petróleo no Pré-sal cresceu de forma exponencial, passando de 16,317 milhões de barris em 2010 para 372,7 milhões de barris em 2016, alcançando, na média, a marca 
de 1 milhão de barris/dia. Em 2018, o Pré-sal representou mais da metade da produção nacional total $(55,24 \%)$, com uma média de 1,5 milhão de barris por dia.

Tabela 1 - Produção de petróleo e participação do Pré-Sal (mil barris)

\begin{tabular}{cccc}
\hline & Pré-sal & Brasil & Participação (\%) \\
\hline 2008 & 2.558 & 663.274 & 0,39 \\
2009 & 6.756 & 711.881 & 0,95 \\
2010 & 16.317 & 749.952 & 2,18 \\
2011 & 44.394 & 768.469 & 5,78 \\
2012 & 62.488 & 754.407 & 8,28 \\
2013 & 110.538 & 738.713 & 14,96 \\
2014 & 179.820 & 822.928 & 21,85 \\
2015 & 280.055 & 889.666 & 31,48 \\
2016 & 372.746 & 918.731 & 40,57 \\
2017 & 469.913 & 956.928 & 49,11 \\
2018 & 521.543 & 944.117 & 55,24 \\
\hline
\end{tabular}

Fonte: Elaboração própria a partir dos dados da ANP $(2018,2019)$.

Por se tratar de uma commodity, o petróleo tem o preço formado por cotações no mercado internacional, por conseguinte, suas alterações afetam diretamente o desempenho das nações exportadoras. O Gráfico 2 traz as variações do preço do petróleo e a evolução das importações e exportações brasileiras em quase duas décadas.

Gráfico 2 - Exportações, importações (US\$ FOB/milhão) no Brasil e preços do petróleo (US\$) (BRENT e WTI) 2000-2019

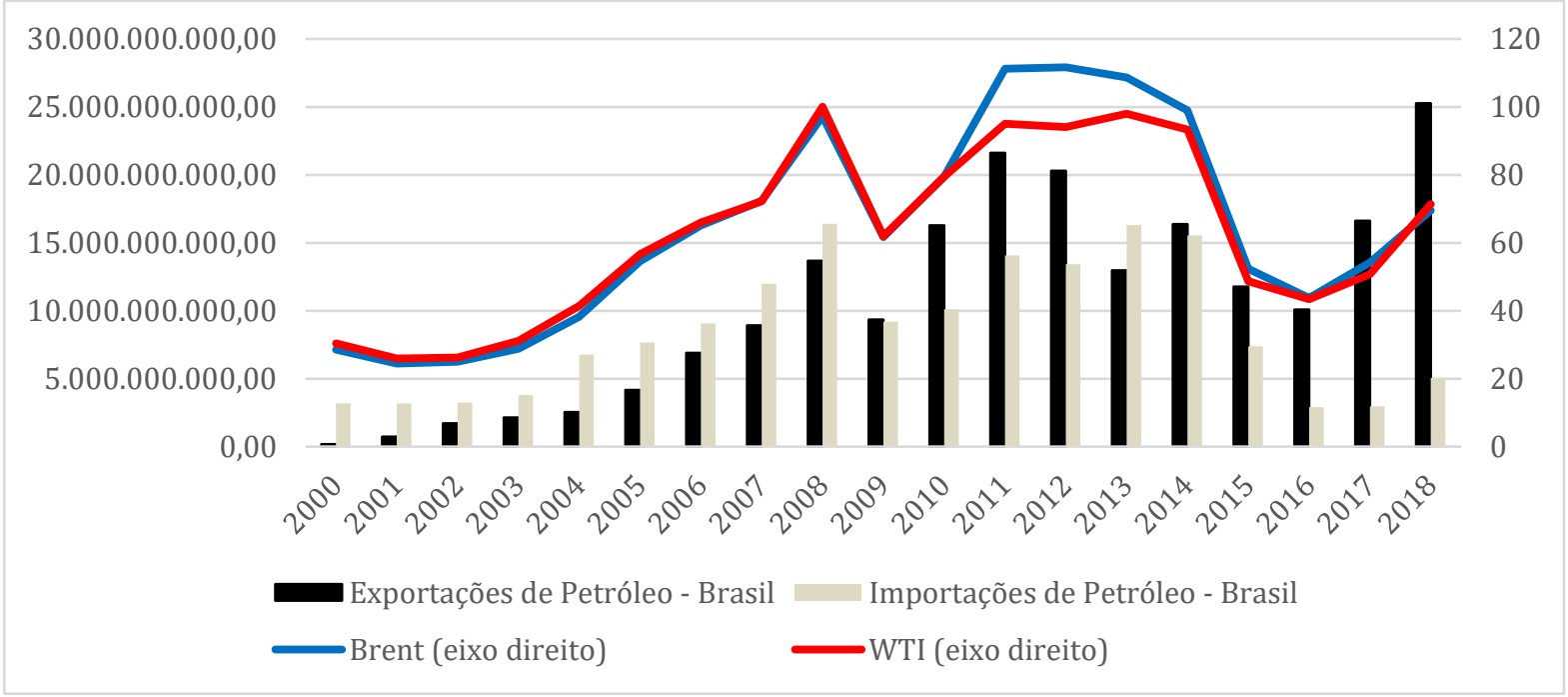

Fonte: Elaboração própria a partir dos dados do BP Group (2019) e MDIC (2019).

Nota: Brent é um padrão para mercados europeus e asiáticos, reunindo mais de 15 graus de petróleo produzidos nos blocos noruegueses e escoceses de Brent, Ekofisk, Oseberg e Forties. WTI é uma marca 
para o hemisfério ocidental, oriundo das extrações de petróleo nos EUA, principalmente no Texas, na Louisiana e na Dakota do Norte.

O preço do petróleo ${ }^{22}$ reflete diretamente o dinamismo do mercado mundial. De 2000 a 2008, a valorização do barril de petróleo foi da ordem de $241 \%$ para o petróleo tipo Brent e $229 \%$ para o WTI, mediante o cenário de aprofundamento da industrialização chinesa e de abundância de liquidez internacional, que culminou no processo de financeirização do mercado de commodities, ou seja, da venda de derivativos vinculados a esses produtos como alternativa de diversificação de riscos.

No entanto, a crise do Subprime norte-americana afetou a economia mundial, reduzindo, a partir de 2009, a demanda internacional por petróleo, cuja parcela recuou em $57 \%$ e levou à queda de $61 \%$ nos preços em um ano. Ambas as variáveis se recuperaram nos anos seguintes, mas a desconfiança e os esforços pela recuperação econômica dos Estados Unidos foram traduzidos pela maior variação do Brent em detrimento do WTI, conforme explícito na diferença entre 2010 e 2014, período em que o Brent atingiu os maiores valores da série histórica (média de US\$111 por barril) (ANP,2018).

A partir de 2015, a realidade foi de queda brusca dos preços do produto em razão de alguns fatores que afetaram o mercado, tais como a ascensão dos EUA como maior produtor de petróleo mundial pela exploração do óleo de xisto, crescendo a oferta global; o aumento de produção e oferta do Iraque; o retorno do Irã após o fim das sanções de acordos nucleares; e a influência da Arábia Saudita tentando manter ou até aumentar sua quota de mercado.

O Gráfico 2 também mostra que, até 2008, as importações brasileiras de petróleo superavam as exportações. No entanto, desde o início da década de 2000, as exportações apresentam crescimento, com ganho de participação no mercado mundial, o que pode indicar um reflexo de melhor estrutura produtiva e de investimentos no setor.

A partir de 2009, o Brasil passa a ter superávits na conta petróleo. Muito desse desempenho favorável deve-se à escalada do preço do produto no mercado internacional. Isso gerou uma série de fatores que foram fundamentais para o avanço do setor, culminando na mudança significativa representada pelos superávits sustentados até o período recente, a saber: demanda global aquecida; mercado indicando favorecimento à commodity energética via preços; investimentos realizados em períodos anteriores, tais como a tecnologia aplicada para exploração em águas profundas.

A Tabela 2 traz os principais parceiros comerciais do Brasil na venda de petróleo a partir de 2009, período em que o país começa a ter superávits comerciais no setor.

\footnotetext{
${ }^{2}$ Segundo a Petrobras (2019), o Pré-sal é uma sequência de rochas sedimentares formadas há mais de 100 milhões de anos no espaço geográfico criado pela separação dos continentes americano e africano, que começou há cerca de 150 milhões de anos. Entre os dois continentes formaram-se, inicialmente, grandes depressões, que deram origem a grandes lagos, onde foram depositadas as rochas geradoras de petróleo do Pré-sal.
} 
Verifica-se que a China é o principal consumidor das exportações brasileiras, representando mais da metade (em 2018) do destino do petróleo bruto nacional. Os Estados Unidos, que entre 2009 e 2014 alternavam com a China como principal importador do petróleo brasileiro, apresentam, desde 2014, queda relativa em sua relação comercial, refletindo os efeitos da "revolução energética" iniciada com a expansão do gás de xisto americano. Em 2018, o país teve participação de apenas $12,38 \%$ nas vendas do Brasil.

Tabela 2 - Principais importadores do petróleo brasileiro (participação percentual no total das vendas brasileiras), 2009-2018

\begin{tabular}{lcccccccccc}
\hline País & $\mathbf{2 0 0 9}$ & $\mathbf{2 0 1 0}$ & $\mathbf{2 0 1 1}$ & $\mathbf{2 0 1 2}$ & $\mathbf{2 0 1 3}$ & $\mathbf{2 0 1 4}$ & $\mathbf{2 0 1 5}$ & $\mathbf{2 0 1 6}$ & $\mathbf{2 0 1 7}$ & $\mathbf{2 0 1 8}$ \\
\hline China & 14,02 & 25,47 & 22,57 & 22,73 & 30,1 & 20,61 & 34,25 & 37,14 & 42,43 & 55,51 \\
EUA & 25,96 & 23,83 & 26,88 & 28,46 & 27,95 & 21,27 & 16,35 & 11,82 & 17,11 & 12,38 \\
Índia & 7,32 & 7,49 & 7,92 & 17,27 & 12,97 & 15,72 & 10,75 & 7,29 & 9,21 & 4,71 \\
Chile & 5,43 & 6,22 & 9,63 & 4,82 & 8,04 & 11,43 & 8,41 & 10,24 & 8,57 & 8,26 \\
Espanha & 2,76 & 2,38 & 2,23 & 2,33 & 4,34 & 2,31 & 4,08 & 5,63 & 6,76 & 9,19 \\
St. Lúcia & 28,79 & 17 & 13,49 & 6,18 & 0,72 & 7,12 & 6,23 & 3,43 & 2,72 & 1,58 \\
\hline
\end{tabular}

Fonte: Elaboração própria a partir dos dados da ANP (2019).

Cabe destacar a relevância dos acordos bilaterais com a região do Caribe, iniciados em 2007. De acordo com MRE (2013), a inauguração da embaixada do Brasil em Castries, capital de Santa Lúcia, em 2007, contribuiu para o estreitamento dos laços e para a diversificação da agenda bilateral com aquele país, no contexto da aproximação política e econômica com toda a região do Caribe. É possível notar os resultados para os anos de 2009 a 2011, em especial para 2009, cuja participação de Santa Lúcia, de acordo com os dados obtidos na ANP (2019), representou a maior parceria comercial do período.

Por fim, ainda que não seja o objeto de estudo do trabalho, também é necessário mencionar os resultados do setor para os derivados. Mercado esse que possui forte valor agregado e necessita ainda de grande desenvolvimento interno, a fim de tornar o país mais competitivo no cenário internacional. No que diz respeito aos resultados dos derivados, a tabela 3 expõe que o Brasil apresenta um perfil dependente mediante valores deficitários para quase todos os anos em análise. Além disso, há forte sugestão do aprofundamento desse comportamento expressas na tabela 3 pela significativa expansão do volume importado a partir dos anos de 2010. Dentre os derivados de maiores demandas internas estão: o NAFTA, no qual o Brasil não apresenta receitas para esse derivado; o Gás Liquefeito de Petróleo (GLP), cujas as receitas, em média, não representam nem $10 \%$ do total dispendido em importação; e o Óleo Diesel, que de forma análoga tem gastos de importação em um montante muitas vezes superior às suas receitas de exportação. 
Tabela 3 - Importações e Exportações de Derivados de Petróleo (MIL US\$ FOB/ valores correntes) (mil $\left.\mathrm{m}^{3}\right)$

\begin{tabular}{|c|c|c|c|c|c|}
\hline \multicolumn{6}{|c|}{ Derivados de Petróleo } \\
\hline & $\begin{array}{l}\text { Importações } \\
\text { (Dispêndios) }\end{array}$ & $\begin{array}{c}\text { Exportações } \\
\text { (Receitas) }\end{array}$ & $\begin{array}{c}\text { Importações } \\
\left(\mathrm{mil} \mathrm{m}^{3}\right)\end{array}$ & $\begin{array}{c}\text { Exportações } \\
\left(\mathrm{mil} \mathrm{m}^{3}\right)\end{array}$ & Saldo $\left(\mathrm{mil} \mathrm{m}^{\mathbf{3}}\right)$ \\
\hline 2000 & $3.227 .470,00$ & $1.854 .038,00$ & $18.256,50$ & $9.771,00$ & $8.485,50$ \\
\hline 2005 & $335.872,00$ & $5.242 .321,00$ & $10.921,60$ & $15.640,80$ & $4.719,20$ \\
\hline 2010 & $12.980 .138,00$ & $7.055 .421,00$ & $27.375,40$ & $13.782,90$ & $13.592,50$ \\
\hline 2015 & $9.710 .278,00$ & $5.022 .099,00$ & $25.724,50$ & $13.482,20$ & $12.242,30$ \\
\hline 2016 & $8.233 .438,00$ & $3.536 .611,00$ & $28.325,90$ & $11.837,90$ & $16.488,00$ \\
\hline 2017 & $12.968 .300,00$ & $4.814 .615,00$ & $35.727,30$ & $12.448,30$ & $23.279,00$ \\
\hline 2018 & $14.697 .227,00$ & $6.768 .108,00$ & $32.756,70$ & $13.241,00$ & $19.515,70$ \\
\hline
\end{tabular}

Fonte: Dados da ANP $(2010,2019)$

Em suma, de forma preliminar, os dados dessa seção ressaltam o aumento do peso do setor nas exportações brasileiras, a menor dependência em relação às importações, o avanço significativo na capacidade produtiva e na participação da parcela da oferta mundial. Tais características, portanto, atribuem um papel importante à atividade e podem contribuir para promover a especialização comercial em petróleo ao longo do tempo.

\section{METODOLOGIA: INDICADORES DE ESPECIALIZAÇÃO COMERCIAL}

A metodologia adotada neste artigo pretende verificar a existência de algum tipo de especialização ou de vantagem comparativa para o Brasil no setor petrolífero. Para tanto, aplica-se o cálculo de alguns indicadores que visam determinar a vantagem comparativa e o posicionamento do setor no mercado externo. Os indicadores avaliados são o Índice de Vantagem Comparativa Revelada (VCR), proposto por Balassa (1989), e o índice de Vantagem Competitiva Revelada (VCR) e o Índice de Posição Relativa no Mercado (POS), sugeridos por Lafay et al. (1999).

O VCR é uma medida comparativa para dados de exportação de um determinado país. Consiste em revelar os setores com vantagens competitivas de um país pela análise das exportações reais. Para determinar se um país possui uma posição favorável em algum setor específico, é necessário verificar a participação relativa das exportações do país naquele setor em relação às exportações totais do país $\left(X_{k i t} / X_{i t}\right)$, isso em razão das exportações do setor no mundo dividido pelas exportações totais do mundo $\left(X_{k w t} / X_{w t}\right)$. O VCR é descrito pela equação 1 , a seguir:

$$
I V C R_{i t}=\frac{X_{k i t} / X_{i t}}{X_{k w t} / X_{w t}}
$$


Em que $X_{k i t}$ é o valor das exportações do setor $k$ do país $i$ no tempo $t, X_{i t}, 0$ valor total das exportações do país no tempo $t, X_{k w t}$, o valor das exportações mundiais para o setor $k$, e $X_{w t}$, o valor total das exportações mundiais no tempo $t$. Quanto maior for o volume exportado de um determinado setor por um país em relação ao volume total mundial exportado desse mesmo setor, maior será a sua vantagem comparativa.

Uma crítica ao indicador de Vantagens Comparativas Reveladas (VCR) de Balassa, tal como em Xavier (2001), alerta que o mesmo leva em consideração apenas as exportações no cálculo da posição competitiva de um setor de um país, sem nenhuma referência aos fluxos de importações. Neste sentido, os indicadores de Vantagem Comparativa Revelada e de Posição Relativa no Mercado, propostos por Lafay et al. (1999), podem expressar os resultados do desempenho do setor petrolífero nacional de forma mais significativa, sendo capaz de captar a mudança (em termos de competitividade) ao considerar também as contribuições do saldo comercial do setor ponderado pelo Produto Interno Bruto (PIB) ao longo do tempo.

A versão do VCR estimada por Lafay et al. (1999) visa avaliar a competitividade entre produtos ou setores em um determinado país, seja qual for o saldo global, que afete $o$ seu conjunto de bens e serviços, permitindo que se aprofunde a análise sobre a tendência de especialização de um país. Nesse sentido, para um produto ou setor $k$ de um país $i$, primeiramente, calcula-se o seu saldo em relação ao PIB $\left(Y_{i}\right)$, ou seja, em relação ao tamanho do mercado nacional.

$$
y_{i k t}=1000 *\left(\frac{X_{i k t}-M_{i k t}}{Y_{i t}}\right)
$$

Em que $y_{i k}$ é a participação do saldo comercial de um setor $k$ do país $i$ no PIB, $X_{i k}$, o valor das exportações do setor $k$ por um país $i, M_{i k}$, o valor das importações do setor $k$ por um país $i$, e $Y_{i}$ o PIB do país $i$ no tempo $t$.

A seguir, definem-se as contribuições do saldo comercial do setor $k$ à balança comercial (equação 3) e desta em relação ao PIB (equações 4 e 5 ).

$$
\begin{aligned}
& g_{i k t}=\left(\frac{X_{i k t}+M_{i k t}}{X_{i t}+M_{i t}}\right) \\
& y_{i k t}=1000 *\left(\frac{X_{i k t}-M_{i k t}}{Y_{i t}}\right)
\end{aligned}
$$

Nessas equações, $X_{i}$ e $M_{i}$ são, respectivamente, exportações e importações totais do país $i$ no tempo $t$.

Assim, pode-se obter:

$$
V C R=f_{i k t}=y_{i k t}-g_{i k t} * y_{i t}
$$


Sendo que $f_{i k t}$ é a vantagem comparativa corrigida pelo PIB.

Por fim, é alcançado o indicador de Vantagem Comparativa Revelada $\left(f_{i k t}\right)$, cujo sinal positivo indica que o país possui vantagem comparativa, ao passo que o sinal negativo sinaliza desvantagem comparativa para o produto ou setor sob avaliação.

Outro indicador relevante é o Índice de Posição Relativa no Mercado (POS), também elaborado por Lafay et al. (1999). Para a determinação da posição de uma nação no mercado internacional de um produto é necessário que se calcule o seu saldo comercial de exportações menos importações do produto $k$, no tempo $n$, do país $i$, em relação ao total do referido produto $k$ comercializado no mundo $W$ (valor total das exportações mais importações mundiais desse produto) em um determinado período de tempo.

Algebricamente, tem-se:

$$
P O S_{i k t}=100 *\left(\frac{X_{i k t}-M_{i k t}}{W_{i t}}\right)
$$

Em que $P O S_{i k t}$ é a posição do país $i$ no mercado mundial do setor $k$ em determinado ano $t, X_{i k t}$ é o valor das exportações do setor $k$, do país $i, M_{i k t}$, o valor das importações do setor $k$ do país $i$, e $W_{i t}$ o valor das exportações mais importações mundiais do setor $k$, em determinado ano $t$.

\section{RESULTADOS}

O Gráfico 3 apresenta os resultados para o Índice de VCR de Balassa ${ }^{33}$. Verificase a trajetória de crescimento do volume de petróleo bruto exportado no período em análise, resultando em um impacto positivo sobre o aguçamento das vantagens comparativas do setor. Neste sentido, observa-se que o país apresentou um índice VCR crescente desde o ano 2000 (VCR =0,067), que se tornou superior a 1 (VCR = 1,113 ) em 2007, indicando que o país passou a apresentar um quadro de vantagem comparativa revelada (especialização) na exportação de petróleo a partir desse ano. Ou seja, nos primeiros anos da década, verifica-se a pouca expressividade das exportações brasileiras de petróleo no contexto mundial, quadro que vai se alterando a partir de meados da década de 2000 e se intensifica depois de 2013, mediante o avanço da participação da exploração das reservas do Pré-sal (ver tabela 2).

Essa evidência sugere que, com o avanço da produção e exportação do petróleo do Pré-sal, o Brasil pôde aprofundar de forma expressiva o peso desse bem na pauta exportadora. Alguns fatores foram determinantes para o aumento da competitividade do petróleo brasileiro, dentre os quais estão: o crescimento do segmento de

\footnotetext{
${ }^{3}$ Até o momento de elaboração desse trabalho algumas plataformas disponibilizavam dados até o período de 2018, portanto, os indicadores de especialização se limitam até esse período.
} 
exploração e produção; o avanço dos investimentos e da tecnologia; a internacionalização da indústria petrolífera nacional e a quebra do monopólio estatal; bem como a elevação dos preços internacionais do petróleo e o aumento da demanda.

Gráfico 3 - Indicador de Vantagem Comparativa Revelada de Balassa, 2000-2018

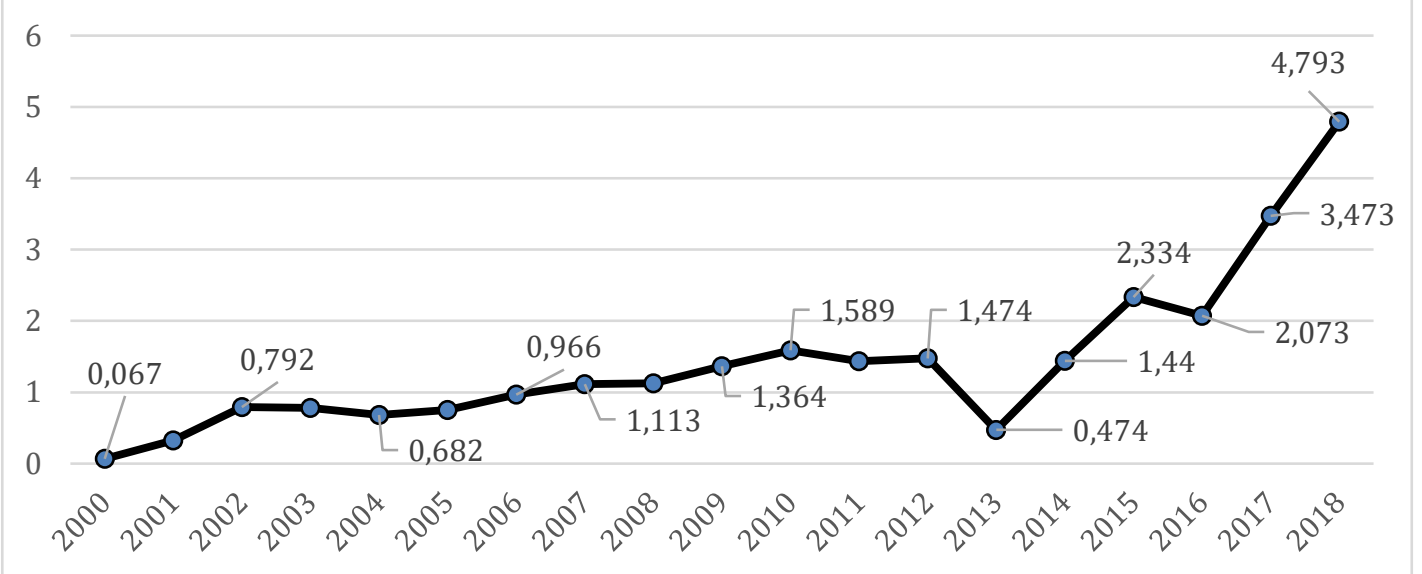

Fonte: Elaboração própria a partir dos dados do MDIC (2019), UN COMTRADE (2019) e WORLD BANK (2019).

A Tabela 4 apresenta os valores correspondentes à contribuição ao saldo, contribuição ao produto, o Índice de Vantagem Comparativa na versão de Lafay e a Posição Relativa no Mercado.

A coluna $1\left(y_{k t}\right)$ representa a participação do saldo comercial do setor em relação ao PIB. Até 2008, os valores negativos revelam o período de maior dependência externa da commodity energética. A partir de 2010, os valores do indicador tornam-se mais significativos $(2,80)$, refletindo o avanço das exportações, principalmente, por tal desempenho ultrapassar no saldo comercial as importações de petróleo bruto, indicando a superação da dependência externa. A partir de 2015, cresce em contribuição de forma expressiva, atingindo o ápice em 2018, com notáveis $10,81 \%$.

Tabela 4 - Indicador de Vantagem Comparativa Revelada e Posição no Mercado, 2000-2018

\begin{tabular}{l|c|c|c|c|c}
\hline & $\mathbf{Y}_{\text {ikt }}$ & $\mathbf{G}_{\text {ikt }}$ & $\mathbf{Y}_{\text {it }}$ & $\mathbf{V C R}$ & POS \\
\hline $\mathbf{2 0 0 0}$ & $-4,62$ & 0,03 & 3,29 & $-4,73$ & $-0,42$ \\
$\mathbf{2 0 0 1}$ & $-4,42$ & 0,04 & 9,22 & $-4,75$ & $-0,39$ \\
$\mathbf{2 0 0 2}$ & $-3,06$ & 0,05 & 28,95 & $-4,46$ & $-0,25$ \\
$\mathbf{2 0 0 3}$ & $-3,01$ & 0,05 & 47,26 & $-5,44$ & $-0,21$ \\
$\mathbf{2 0 0 4}$ & $-6,36$ & 0,06 & 56,54 & $-9,87$ & $-0,42$ \\
$\mathbf{2 0 0 5}$ & $-3,93$ & 0,07 & 54,65 & $-7,52$ & $-0,25$ \\
$\mathbf{2 0 0 6}$ & $-1,96$ & 0,07 & 43,96 & $-5,25$ & $-0,12$ \\
$\mathbf{2 0 0 7}$ & $-2,21$ & 0,08 & 30,87 & $-4,69$ & $-0,15$
\end{tabular}




\begin{tabular}{c|c|c|c|c|c}
$\mathbf{2 0 0 8}$ & $-1,60$ & 0,09 & 16,14 & $-3,02$ & $-0,09$ \\
$\mathbf{2 0 0 9}$ & 0,09 & 0,07 & 14,97 & $-0,97$ & 0,01 \\
$\mathbf{2 0 1 0}$ & 2,80 & 0,07 & 6,26 & 2,34 & 0,27 \\
$\mathbf{2 0 1 1}$ & 2,88 & 0,08 & 8,47 & 2,20 & 0,24 \\
$\mathbf{2 0 1 2}$ & 2,79 & 0,08 & 4,88 & 2,41 & 0,22 \\
$\mathbf{2 0 1 3} *$ & $-1,36$ & 0,06 & 2,29 & $-1,51$ & $-0,06$ \\
$\mathbf{2 0 1 4}$ & 0,34 & 0,08 & $-2,03$ & 0,49 & 0,03 \\
$\mathbf{2 0 1 5}$ & 2,44 & 0,06 & 8,38 & 1,97 & 0,31 \\
$\mathbf{2 0 1 6}$ & 3,99 & 0,04 & 22,53 & 3,05 & 0,58 \\
$\mathbf{2 0 1 7}$ & 6,65 & 0,06 & 25,97 & 5,19 & 0,97 \\
$\mathbf{2 0 1 8}$ & 10,81 & 0,08 & 20,24 & 9,24 & 1,33
\end{tabular}

Fonte: Elaboração própria a partir dos dados do MDIC (2019), UM CONTRADE (2019) e WORLD BANK (2019).

* A produção de petróleo da Petrobras ficou estagnada em 2013 em meio a paradas de manutenção de suas plataformas, de acordo com algumas normas de funcionamento mais rígidas da agência reguladora.

A coluna $2\left(G_{i k t}\right)$ expressa a relação do fluxo comercial/corrente de comércio (exportações mais importações) do setor de petróleo em razão do fluxo comercial total. Dividindo o período em três grupos de seis anos, têm-se que a média da participação do fluxo comercial de petróleo bruto de 2000 a 2006 é de $5 \%$, sendo que até 2008 a principal contribuição do fluxo era via importações. Entre 2007 e 2012 a participação cresce para $8 \%$, puxada pelo crescimento das exportações, contudo volta a cair de 2013 a 2018 para 6\%, dessa vez por uma redução das importações de petróleo bruto.

A coluna $3\left(y_{i t}\right)$ refere-se à contribuição do saldo comercial das exportações totais em relação ao PIB. Percebe-se que o boom das commodities, a partir de 2002, impulsionado pelo avanço do processo da industrialização chinesa, aliado ao cenário de maior liquidez internacional contribuíram fortemente para o desempenho exportador brasileiro. Tal trajetória de crescimento da contribuição das exportações é interrompida a partir da crise de 2008, que afetou o cenário internacional propagando seus efeitos por mais alguns anos, e, posteriormente, pela desaceleração do crescimento chinês.

Portanto, a contribuição do saldo comercial, que, em 2007, era de $30,87 \%$, se reduz de forma acentuada até chegar em 2014, com -2,03\%, ano de déficit da balança comercial brasileira. A recuperação do saldo comercial, a partir de 2015, deve-se principalmente à queda das importações, refletindo os efeitos da crise interna e da instabilidade política instaurada, que, por conseguinte, reduzem a capacidade de importar.

A quarta coluna traz os resultados para o indicador de Vantagens Comparativas Reveladas na versão estimada por Lafay et al. (1999). Assim, até 2008, a dependência externa brasileira evidenciada pelos sucessivos déficits setoriais não possibilitava considerar o mercado de petróleo bruto uma vantagem comparativa nacional. Dessa forma, os valores pouco expressivos das exportações nos primeiros anos do século 
não eram capazes de agregar relevante participação na parcela de contribuição do fluxo comercial. Em contrapartida, o fluxo do comércio total crescia fortemente induzido pelo bom retrospecto do período para as commodities.

No entanto, a partir de 2010, a situação se inverte. O desempenho do setor se dá mediante contínuos superávits comerciais, exceto em 2013, de modo que as transformações estruturais internas combinadas com os fatores de demanda externa conduzem a um processo de vantagem comparativa nacional, no qual os valores crescentes, até o ápice em $2018(\mathrm{VCR}=9,24)$, indicam um processo em curso de especialização em exportações de petróleo bruto.

Parte desse retrospecto favorável pode ser atribuído à alta produtividade alcançada pela descoberta e exploração das reservas do Pré-sal, que possibilitou um expressivo crescimento produtivo. Além disso, esse progresso do setor representa um salto qualitativo em termos de tecnologia desenvolvida e empregada tanto para a descoberta de novas fontes, quanto para a melhoria na extração e, por conseguinte, para um avanço competitivo no cenário internacional ${ }^{4}$.

Diante dessa maior intensidade produtiva, é natural que o país tenha uma melhora no cenário internacional. Contudo, antes, é preciso levar em consideração que o posicionamento dos setores de um país no mercado mundial está diretamente associado à evolução desse mercado, isto é, a uma resposta direta à demanda internacional por esse bem. A demanda que, ao arbitrar a quantidade a ser importada, define a posição competitiva da indústria, portanto, capaz de ratificar (ou não) as ações produtivas, comerciais e de marketing que as empresas tenham realizado.

O Gráfico 4 expõe a evolução do indicador de Posição Relativa no Mercado. Os resultados negativos para o indicador até 2008 indicam que o Brasil esteve em uma posição desfavorável no mercado internacional, particularmente por sua dependência externa pelo petróleo, cuja dinâmica de importação superava o desempenho exportador. Gradativamente, à medida que o país modernizava sua estrutura produtiva setorial, as relações comerciais com a China se intensificavam e as atividades de exploração do Pré-sal começavam a trazer resultados, o indicador passa a refletir a melhora que o setor experimentava. Portanto, os valores positivos indicam a transformação setorial em favor do mercado de petróleo bruto brasileiro.

\footnotetext{
${ }^{4}$ Destaca-se que, para descobrir essas reservas e operar com eficiência em águas ultraprofundas, a Petrobras desenvolveu tecnologia própria e atuou em parceria com fornecedores, universidades e centros de pesquisa, contratando sondas de perfuração, plataformas de produção, navios e submarinos com recursos que movimentam toda a cadeia da indústria de energia (PETROBRAS, 2019).
} 
Gráfico 4 - Posição Relativa de Mercado, 2000-2018

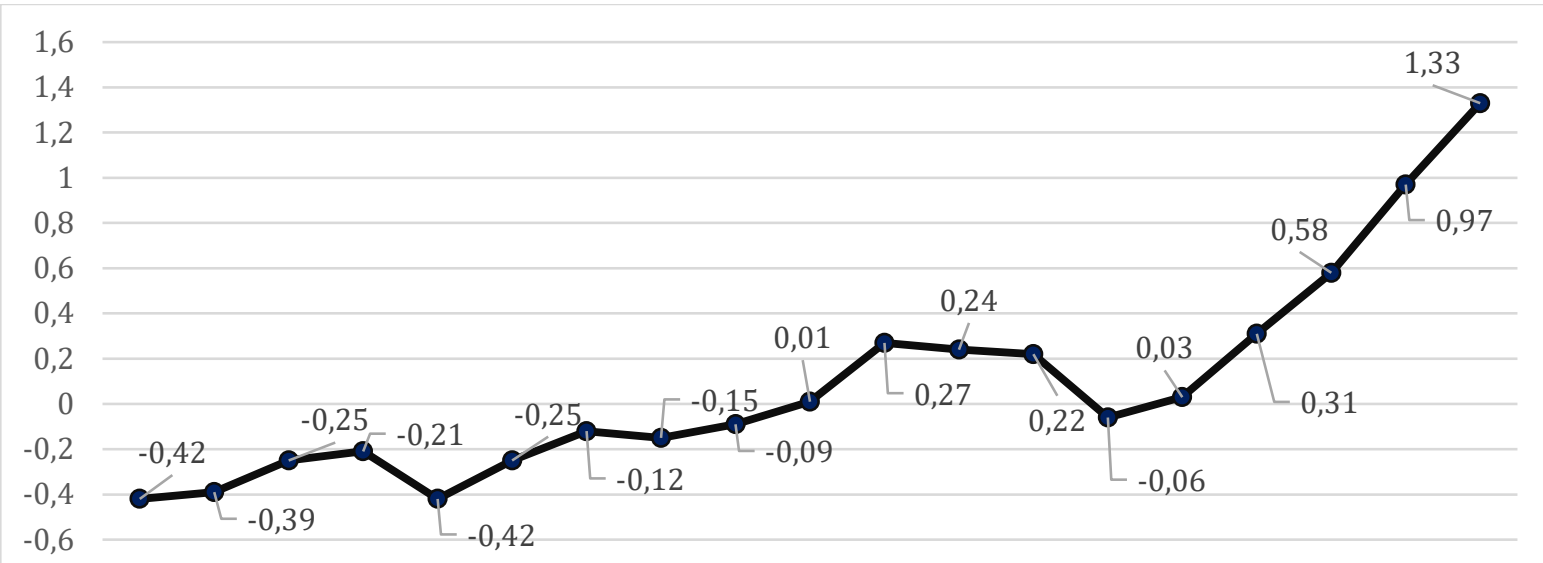

2000200120022003200420052006200720082009201020112012201320142015201620172018

Fonte: Elaboração própria a partir dos dados BP Group (2019) e UN COMTRADE (2019).

Um ponto a ser observado se dá quanto ao momento em que o Brasil obtém a melhora no cenário internacional. A partir de 2013, o mercado internacional apresenta queda nas importações e exportações, e, paralelamente, o indicador POS brasileiro desponta positivamente. Metodologicamente (ver equação 6) isso acontece, pois na base de cálculo do indicador tem-se uma redução do denominador, representado por $W_{k}^{n}$ (valor das exportações mais importações mundiais do setor), por efeito da redução dos preços do petróleo, enquanto o numerador cresce em razão da redução das importações brasileiras, permitindo maior saldo comercial. Portanto, as transformações setoriais internas promovidas nos anos anteriores possuem grande mérito na melhora brasileira no mercado internacional.

Os resultados dos indicadores elaborados sugerem um processo em curso de especialização brasileira nas exportações de petróleo bruto, tendo em vista que os valores apresentados possuem tendência crescente, no sentido de melhoria da vantagem comparativa do setor no país. Além disso, corroboram para a perspectiva de aprofundamento setorial os dados do desempenho do setor; as mudanças qualitativas na estrutura produtiva adotadas no período em análise; a descoberta e exploração do recurso no Pré-sal e a perspectiva de se retomar os investimentos no futuro a partir, sobretudo, da recuperação da saúde financeira e melhora institucional da Petrobras.

Cabe destacar que, embora a teoria econômica retrate possíveis efeitos deletérios ao crescimento dos países especializados em recursos naturais, esta é uma estratégia que deve ser vista não somente por sua perspectiva negativa. É preciso frisar que o setor petrolífero é caracterizado por fortes encadeamentos com outros segmentos da economia, podendo gerar externalidades e transbordamentos positivos em razão do avanço tecnológico inerente à exploração do recurso. Neste sentido, Veríssimo (2019) ressalta que, no caso brasileiro, esta pode ser uma boa oportunidade para alavancar os efeitos de transbordamento da atividade, visto que a exploração em 
águas profundas requer o estímulo à inovação, com potencial para o país se tornar líder em tecnologia offshore e exportador de bens e serviços na área. Todavia, esse processo precisa ser enfrentado internamente, sob risco de o país se tornar ainda mais dependente da tecnologia de fornecedores estrangeiros.

\section{CONSIDERAÇÕES FINAIS}

Este trabalho investigou a hipótese de especialização das exportações brasileiras em petróleo bruto, buscando destacar os aspectos que conferiram desempenho significativo do setor ao longo das duas últimas décadas. A relevância da investigação parte da preocupação abordada pela literatura relativa à especialização em recursos naturais, a qual adverte que países especializados em bens primários tendem a apresentar baixas taxas de crescimento econômico no longo prazo.

Neste sentido, foram elaborados indicadores de especialização setorial das exportações (duas versões do indicador de Vantagens Comparativas Reveladas e um indicador de Posição Relativa no Mercado) com dados do período de 2000 a 2018. Os resultados obtidos sugerem um processo de especialização em curso nas exportações de petróleo para o Brasil, tendo em vista que os valores apresentados possuem tendência crescente, no sentido de melhoria da vantagem comparativa do setor para o país.

Corroboram para a perspectiva de aprofundamento setorial os dados do desempenho do setor, as mudanças qualitativas na estrutura produtiva adotadas em anos anteriores, a descoberta e exploração do petróleo no Pré-sal, e a perspectiva de se retomar os investimentos no futuro, a partir, sobretudo, da recuperação da saúde financeira e melhora institucional da Petrobras.

Cabe destacar que o setor enfrentou um contexto político-institucional adverso a partir de 2014, com a deflagração da Operação Lava Jato, a qual retrata a maior investigação de corrupção no país e cuja atuação envolve a Petrobras. Sobre isso, constata-se que, de imediato, o setor petrolífero nacional sofreu um revés quanto às projeções de crescimento, mas, aos poucos, o cenário está se restabelecendo, ao ponto de que, em 2018, a Petrobras retorna aos status de maior empresa da América Latina. De fato, mesmo lidando com um cenário institucional crítico, a adoção de uma estratégia direcionada ao aprofundamento da exploração e produção focalizada no Pré-sal se mostrou relevante, permitindo um crescimento da produção, ainda que aquém das perspectivas projetadas nos períodos anteriores à Operação Lava Jato, enquanto as pendências institucionais se encaminham para um cenário de estabilidade, permitindo a retomada da estratégia de crescimento/investimento do setor.

Com base nas evidências dos indicadores de especialização, verifica-se que o setor petrolífero tem potencial para desempenhar um papel de vantagem produtiva e comercial significativa para o Brasil. Embora o período em análise (2000 a 2018) não seja ainda suficiente para apontar uma especialização consistente a longo prazo, os 
resultados indicam um processo em curso. Portanto, medidas de desenvolvimento setorial com intuito de evitar os efeitos negativos de uma especialização regressiva devem ser adotadas, tais como fomento de cadeias produtivas; aproximação da fronteira tecnológica e estímulo à inovação, sobretudo, na exploração em águas profundas; desenvolvimento do setor de refino; e diversificação de parceiros comerciais.

Essas são algumas das principais janelas de oportunidades que, se bem aproveitadas, possibilitam vislumbrar o desenvolvimento robusto do setor e alavancar a reboque outros setores por meio de trasbordamentos e externalidades positivas.

\section{REFERÊNCIAS}

ANP. AGÊNCIA NACIONAL DO PETRÓLEO, GÁS NATURAL E BIOCOMBUSTÍVEIS. Anuário Estatístico Brasileiro do Petróleo, Gás Natural e Biocombustíveis. 2018. Disponível em: http://www.anp.gov.br/. Acesso em: 05/11/2019.

ANP. AGÊNCIA NACIONAL DO PETRÓLEO, GÁS NATURAL E BIOCOMBUSTÍVEIS. Anuário Estatístico Brasileiro do Petróleo, Gás Natural e Biocombustíveis. 2019. Disponível em: http://www.anp.gov.br/. Acesso em: 05/11/2019.

\section{BALASSA, B. Comparative advantage, trade policy and economic} development. New York: New York University, 1989.

BP GROUP. BP Statistical Review of World Energy. 67 ed. June, 2019. Disponível em: $\quad$ https://www.bp.com/content/dam/bp/businesssites/en/global/corporate/pdfs/energy-economics/statistical-review/bp-stats-review2018-full-report.pdf. Acesso em: 21/06/2019.

BRESSER-PEREIRA, L. C. A doença holandesa. In: BRESSER-PEREIRA, L. C. (org.). Globalização e competição: por que alguns países emergentes têm sucesso e outros não. Rio de Janeiro, Elsevier, p. 141-171, 2009.

CORDEN, W. M.; NEARY, J. P. Booming sector and de-industrialization in a small open economy. Economic Journal, v. 92, n. 368, dez. 1982.

CRUZ, M. J. V.; NAKABASHI, L.; PORCILE, J. G.; SCATOLIN, F. D. Uma análise do impacto da composição ocupacional sobre o crescimento da economia brasileira. Revista Economia. Dezembro, 2007.

EPE. EMPRESA DE PESQUISA ENERGÉTICA. Bolétim de conjuntura. Matriz Energética e Elétrica. 2019. Disponível em: http://www.epe.gov.br/pt/abcdenergia/matriz-energetica-e-eletrica. Acesso em: 10 out. 2019.

FRANKEL, J. The natural resource curse: a survey. Cambridge, MA: National Bureau of Economic Research. NBER Working Paper 15836. March, 2010. https://doi.org/10.3386/w15836. 
IEA. INTERNATIONAL ENERGY AGENCY. World Energy Outlook 2009. Executive Summary. 2009. Disponível em: http://www.iea.org/ textbase/npsum/weo2009sum.pdf. Acesso em: 05/11/2018.

LAFAY, G.; HERZOG, C.; FREUDENBERG, M.; DENIZ, U. Nations et mondialisation. Paris: Economica, p. 67-334, 1999.

MDIC. MINISTÉRIO DO DESENVOLVIMENTO, INDÚSTRIA E COMÉRCIO EXTERIOR. Estatísticas do Comércio Exterior. Disponível em: http://www.desenvolvimento.gov.br. Acesso em: 30 jan. 2020.

MRE. MINISTÉRIO DAS RELAÇÕES EXTERIORES. Países e entes com os quais o Brasil mantém relações diplomáticas. 2013. Disponível em: http://www.itamaraty.gov.br/pt-BR/ficha-pais/6472-santa-lucia. Acesso em: 08 set. 2019.

NAKABASHI, L; CRUZ, M. J. V; SCATOLIN, F. D. Efeitos do Câmbio e Juros sobre as Exportações da Indústria Brasileira. Revista Economia Contemporânea, Rio de Janeiro, v. 12, n. 3, p.433-461, set. 2008.

NASSIF, A.; CASTILHO, M. Trade Patterns in a Globalised World:Brazil's Recent Trajectory Towards Regressive Specialisation. Conference: 21st Forum For Macroeconomics And Macroeconomic Policies, Berlin,germany, v. 21, p.1-68, set. 2017.

OREIRO, J. L.; FEIJÓ, C. A. Desindustrialização: Conceituação, Causas, Efeitos e o Caso Brasileiro. Revista de Economia Política, v. 30, no. 2, Abr-Jun, 2010.

PETROBRAS. Nossas atividades. Áreas de atuação. Exploração e Produção de Petróleo e Gás. 2019. Disponível em: http://www.petrobras.com.br/pt/nossasatividades/areasde- atuacao/exploracao-e-producao-de-petroleo-e-gas/. Acesso em 26 out. 2019.

ROBINSON, J. A.; TORVIK, R.; VERDIER, T. Political foundations of the resource curse. Journal of Development Economics, v. 79, n. 2, p. 447-468, 2006.

SACHS, J. D.; WARNER, A. M. Natural resource abundance and economic growth. National Bureau of Economic Research, NBER Working Paper No. 5398. December, 1995.

UN COMTRADE. UNITED NATIONS CONFERENCE ON TRADE AND DEVELOPMENT. Statistics. 2019. Disponível em: https://unctad.org/en/Pages/statistics.aspx. Acesso em: 20/03/2019.

VAN DER PLOEG, F. Natural resources: curse or blessing? Journal of Economic Literature, v.42, n. 2, p. 366-420, 2011.https://doi.org/10.1257/jel.49.2.366.

VERÍSSIMO, M. P. Exportações de petróleo e a hipótese da Maldição dos Recursos Naturais no Brasil. Revista Brasileira De Inovação, 18(1), p. 63-88, 2019. https://doi.org/10.20396/rbi.v18i1.8653612. 
XAVIER, L. C. Padrões de Especialização e Saldos Comerciais no Brasil. Anais do XXIX Encontro Nacional de Economia [Proceedings of the 29th Brazilian Economics Meeting]049, ANPEC - Associação Nacional dos Centros de Pós-Graduação em Economia [Brazilian Association of Graduate Programs in Economics]. Salvador, Dezembro, 2001. 